Int. J. Electrochem. Sci., 14 (2019) 9695 - 9703

\title{
Investigation of $\mathrm{Al}_{2} \mathrm{O}_{3}$ Crucible Contamination induced by extra $\mathrm{Li}_{2} \mathrm{CO}_{3}$ during $\mathrm{Li}_{7} \mathrm{La}_{3} \mathrm{Zr}_{2} \mathrm{O}_{12}$ Solid Electrolyte Sintering process
}

\author{
Weijie Lan ${ }^{l}$, Dongliang Lu ${ }^{2}$, Ruirui Zhao ${ }^{1, *}$, Hongyu Chen ${ }^{1, *}$ \\ ${ }^{1}$ School of Chemistry and Environment, South China Normal University, Guangdong Guangzhou, \\ 510006, China \\ ${ }^{2}$ Guangdong Polytechnic of Environmental Protection Engineering, Foshan, 528216, China \\ *E-mail: zhaoruirui@m.scnu.edu.cn, hychen@scnu.edu.cn
}

doi: $10.20964 / 2019.10 .22$

Received: 23 May 2019 / Accepted: 29 July 2019 / Published: 30 August 2019

\begin{abstract}
$\mathrm{Al}_{2} \mathrm{O}_{3}$ crucible is commonly used during the sintering process of $\mathrm{Li} 7 \mathrm{La}_{3} \mathrm{Zr}_{2} \mathrm{O}_{12}$ pellets, which always introduces unintentional Al-containing impurities to the final product. Rare investigations are focused on the mechanism of this crucible contamination up to now. Based on the study in this work, it is found that the extra $\mathrm{Li}_{2} \mathrm{CO}_{3}$ in the $\mathrm{Li}_{7} \mathrm{La}_{3} \mathrm{Zr}_{2} \mathrm{O}_{12}$ powder is a crucial factor in forming this kind of Al-containing impurities in the obtained pellets. The pyrolytic $\mathrm{Li}_{2} \mathrm{O}$ from $\mathrm{Li}_{2} \mathrm{CO}_{3}$ will react with $\mathrm{Al}_{2} \mathrm{O}_{3}$ at high temperature, forming liquid $\mathrm{Li}-\mathrm{Al}-\mathrm{O}$ eutectic and further promoting the dissolution of aluminum oxide crucible. Besides, the extra $\mathrm{Li}_{2} \mathrm{CO}_{3}$ can also affect the compactness and the distribution of $\mathrm{Al}$ element in the pellets, resulting in crystal structure transformation.
\end{abstract}

Keywords: $\mathrm{Li}_{2} \mathrm{CO}_{3} ; \mathrm{Li}_{7} \mathrm{La}_{3} \mathrm{Zr}_{2} \mathrm{O}_{12}$ garnet; gain conductivity; solid-state electrolyte

\section{FULL TEXT}

(C) 2019 The Authors. Published by ESG (www.electrochemsci.org). This article is an open access article distributed under the terms and conditions of the Creative Commons Attribution license (http://creativecommons.org/licenses/by/4.0/). 